\title{
ANÁLISE TERRITORIAL DA SUB-BACIA GRUPIARA, EM LAVRAS (MG), SEGUNDO AS EXIGÊNCIAS DO CÓDIGO FLORESTAL BRASILEIRO (LEI 12.651/2012).
}

\author{
Luiz Otávio Moras Filho ${ }^{1}$
}

\author{
Ana Luísa Alves Cabral ${ }^{2}$
}

\section{Luís Antônio Coimbra Borges ${ }^{3}$}

RESUMO: O presente trabalho consiste em um estudo de caso da sub-bacia Grupiara, no município de Lavras (MG) em consonância às normas vigentes na Lei $n^{\circ}$ 12.651/2012. Estudos com foco na análise da paisagem são importantes para se caracterizar adequadamente a ocupação de bacias hidrográficas segundo as aptidões e às vulnerabilidades ambientais. O Código Florestal brasileiro, além de outras inúmeras atribuições, define áreas protegidas no interior das propriedades rurais do país, por meio da instituição das Áreas de Preservação Permanente e Reserva Legal. Sendo assim, foram elaborados diversos mapas, no intuito de gerar a rede de drenagem do município, extrair a sub-bacia em estudo, delimitar as Áreas de Preservação Permanente (APP) e propor formas diferenciadas de alocação das Reservas Legais. A sub-bacia em estudo possui área de 408,47 ha, sendo 68,61 ha de APP que, teoricamente deveriam ser protegidas. Porém, na prática, apenas 38,29 ha apresentam cobertura composta por fragmentos florestais, o que significa que $44,19 \%$ das áreas estão em descordo com a lei ambiental.

Palavras-chave: Código Florestal. Áreas de Preservação Permanente. Sensoriamento Remoto.

\footnotetext{
${ }^{1}$ Bacharel em Engenharia Florestal, UFLA. analuisa.cabral@outlook.com.

2 Bacharel em Engenharia Florestal, UFLA. lomf_22@hotmail.com.

${ }^{3}$ Professor Adjunto do Departamento de Ciências Florestais, UFLA. luis.borges@dcf.ufla.br.
} 


\section{INTRODUÇÃO}

O Brasil é um dos países que apresenta maior diversidade biológica no mundo, pois abriga, segundo SILVA et al. (2011), pelo menos $20 \%$ das espécies do planeta, com altas taxas de endemismo para diferentes grupos taxonômicos. Isso implica em uma maior responsabilidade no que se diz respeito à conservação dos recursos naturais do planeta.

Reconhecendo essa importância, a legislação brasileira tem avançado cada vez mais, tornando os mecanismos legais de proteção ao meio ambiente mais efetivos, como na aprovação da Lei no 12.651, de 25 de maio de 2012, que dispõe sobre a proteção da vegetação nativa e, entre outras funções, revoga a Lei ํㅜ 4.771, de 15 de setembro de 1965, que instituía o Código Florestal. Com a publicação dessa lei, foram estabelecidas regras mais criteriosas e específicas para garantir a proteção, conservação e recuperação do meio ambiente, além de assegurar o uso sustável dos bens e serviços florestais.

Nesse contexto, o Código Florestal contém instrumentos de imensa importância para assegurar a conservação do meio ambiente, que são as áreas de preservação permanente (APP).

De acordo com o artigo 3ํ do Código Florestal (Lei ํㅜ 12.651, de 25 de maio de 2012), entende-se como APP toda e qualquer área protegida, coberta ou não por vegetação nativa, com a função ambiental de preservar os recursos hídricos, a paisagem, a estabilidade geológica e a biodiversidade, facilitar o fluxo gênico de fauna e flora, proteger o solo e assegurar o bem-estar das populações humanas.

No entanto, apesar da relevância dessas áreas, ainda existem algumas barreiras para que essas exigências sejam cumpridas pelos detentores de imóveis rurais, como no caso de pequenas propriedades onde se limita a área útil para cultivo agrícola, um problema de diversos municípios de Minas Gerais, inclusive Lavras, definido como área demonstrativa para o presente trabalho.

Diante desse impasse, surge a necessidade de estudos mais aprofundados para avaliar a situação em que esses espaços protegidos se encontram, através de um estudo de caso em uma sub-bacia do município, observando se as normas ambientais estão sendo respeitadas em suas respectivas APP.

\section{OBJETIVOS}

Delimitar o município de Lavras e realizar o macrozoneamento do mesmo, no intuito de diferenciar área rural e urbana; 
Gerar o modelo de rede de drenagem da região, com a finalidade de delimitar uma subbacia experimental para as análises cabíveis a este trabalho;

Delimitar as APP da região de estudo (de acordo com o novo do Código Florestal de 2012) e classificar o uso e ocupação do solo nessas áreas, podendo assim estimar o que está sendo preservado, contrastando com os limites teóricos previstos nessa lei;

\section{REFERENCIAL TEÓRICO}

Área protegida, segundo o artigo $2^{\circ}$ da Convenção da Diversidade Biológica (CDB), "significa uma área definida geograficamente que é destinada, ou regulamentada, e administrada para alcançar objetivos específicos de conservação".

Essas áreas protegidas vêm sendo retratadas e redefinidas desde o século $\mathrm{XVI}$, onde as Ordenações Manuelinas e Filipinas estabeleceram regras e limites para exploração de terras, águas e vegetação, até a atualidade, onde nos encontramos em um ano onde houve a publicação da mais recente resolução do Código Florestal Brasileiro. Essa resolução foi sancionada pela Presidenta Dilma Rousseff, através da publicação da Lei nº 12.651 e da Medida Provisória nº 571, publicadas no dia 25 de maio de 2012,

Entre inúmeras funções, essa lei trata das APP, áreas de relevante importância ao meio ambiente, que são definidas do artigo $3^{\circ}$ da seguinte forma:

Art. 3ํㅜ Para os efeitos desta Lei, entende-se por:

(...)

II - Área de Preservação Permanente - APP: área protegida, coberta ou não por vegetação nativa, com a função ambiental de preservar os recursos hídricos, a paisagem, a estabilidade geológica e a biodiversidade, facilitar o fluxo gênico de fauna e flora, proteger o solo e assegurar o bem-estar das populações humanas; (BRASIL, 2012)

Através da análise do Código Florestal no que se diz respeito à delimitação e aos tipos de APP, observar-se que essas áreas podem ser agrupadas em relação ao seu caráter de proteção, sendo que os quatro primeiros incisos do art. 4ำ visam à proteção das águas e os outros sete visam à proteção do solo. Tendo em vista esses grupos de importância, esse artigo delimitou como APP:

Art. 4ํㅡㄹ Considera-se Área de Preservação Permanente, em zonas rurais ou urbanas, para os efeitos desta Lei:

I - as faixas marginais de qualquer curso d'água natural, desde a borda da calha do leito regular, em largura mínima de: 


\begin{tabular}{cc} 
Quadro 01: Larguras das APP em relação às Larguras dos cursos d'água \\
\hline Largura do curso d'água & Largura da APP \\
\hline$<10 \mathrm{~m}$ & $30 \mathrm{~m}$ \\
$10-50 \mathrm{~m}$ & $50 \mathrm{~m}$ \\
$50-200 \mathrm{~m}$ & $100 \mathrm{~m}$ \\
$200-600 \mathrm{~m}$ & $200 \mathrm{~m}$ \\
$>600 \mathrm{~m}$ & $500 \mathrm{~m}$ \\
\hline
\end{tabular}

II - as áreas no entorno dos lagos e lagoas naturais, em faixa com largura mínima de:

a) 100 (cem) metros, em zonas rurais, exceto para o corpo d'água com até 20 (vinte) hectares de superfície, cuja faixa marginal será de 50 (cinquenta) metros;

b) 30 (trinta) metros, em zonas urbanas;

III - as áreas no entorno dos reservatórios d'água artificiais, na faixa definida na licença ambiental do empreendimento, observado o disposto nos $\S \S 1^{\circ}$ e $2^{\circ}$;

IV - as áreas no entorno das nascentes e dos olhos d'água perenes, qualquer que seja sua situação topográfica, no raio mínimo de 50 (cinquenta) metros;

$\mathrm{V}$ - as encostas ou partes destas com declividade superior a $45^{\circ}$, equivalente a $100 \%$ (cem por cento) na linha de maior declive;

$\mathrm{VI}$ - as restingas, como fixadoras de dunas ou estabilizadoras de mangues;

VII - os manguezais, em toda a sua extensão;

VIII - as bordas dos tabuleiros ou chapadas, até a linha de ruptura do relevo, em faixa nunca inferior a 100 (cem) metros em projeções horizontais;

IX - no topo de morros, montes, montanhas e serras, com altura mínima de 100 (cem) metros e inclinação média maior que $25^{\circ}$, as áreas delimitadas a partir da curva de nível correspondente a $2 / 3$ (dois terços) da altura mínima da elevação sempre em relação à base, sendo esta definida pelo plano horizontal determinado por planície ou espelho d'água adjacente ou, nos relevos ondulados, pela cota do ponto de sela mais próximo da elevação;

$X$ - as áreas em altitude superior a 1.800 (mil e oitocentos) metros, qualquer que seja a vegetação;

$\mathrm{XI}$ - em veredas, a faixa marginal, em projeção horizontal, com largura mínima de 50 (cinquenta) metros, a partir do limite do espaço brejoso e encharcado.

(Adaptado de BRASIL, 2012)

Ainda se tratando de APP, os incisos presentes no artigo 6 consideram também as áreas que apresentem riscos, que servem de proteção ou que asseguram o bem-estar da população, sendo instituídas pelo Poder Público.

Art. 6을 Consideram-se, ainda, de preservação permanente, quando declaradas de interesse social por ato do Chefe do Poder Executivo, as áreas cobertas com florestas ou outras formas de vegetação destinadas a uma ou mais das seguintes finalidades:

I - conter a erosão do solo e mitigar riscos de enchentes e deslizamentos de terra e de rocha;

II - proteger as restingas ou veredas;

III - proteger várzeas;

IV - abrigar exemplares da fauna ou da flora ameaçados de extinção;

V - proteger sítios de excepcional beleza ou de valor científico, cultural ou histórico;

$\mathrm{VI}$ - formar faixas de proteção ao longo de rodovias e ferrovias;

VII - assegurar condições de bem-estar público; 
VIII - auxiliar a defesa do território nacional, a critério das autoridades militares. IX - proteger áreas úmidas, especialmente as de importância internacional. (BRASIL, 2012)

Quanto ao regime de proteção dessas áreas, vale ressaltar que:

- A vegetação situada em APP deverá ser mantida pelo proprietário da área;

- Tendo ocorrido supressão de vegetação na APP, o proprietário é obrigado a promover a recomposição da vegetação, ressalvados os usos autorizados pela lei;

- A intervenção ou a supressão em APP somente ocorrerá nas hipóteses de utilidade pública, de interesse social ou de baixo impacto ambiental;

- É permitido o acesso de pessoas e animais às APP para obtenção de água e para realização de atividades de baixo impacto ambiental;

- Em relação a uso antrópico consolidado em APP, a MP № 571 de 2012 autorizou, exclusivamente, a continuidade das atividades agrossilvipastoris, de ecoturismo e de turismo rural em áreas rurais consolidadas até 22 de julho de 2008, além de outras possibilidades consideradas irrelevantes ao entendimento desse trabalho;

De posse dessas informações, torna-se mais fácil compreender os limites geográficos das APP e sua vital importância para o meio ambiente.

\section{MATERIAL E MÉTODOS}

\subsection{Pesquisa bibliográfica}

A pesquisa bibliográfica pode ser considerada o primeiro passo da pesquisa científica, buscando harmonizar os vários pontos de vista, gerando uma visão sensata e útil, sob o aspecto informativo, do problema em estudo (BORGES et al., 2009).

Partindo desse pressuposto, buscou-se realizar um estudo aprofundado das principais mecanismos legais a respeito da conservação e proteção do meio ambiente, sejam estes leis, decretos, medidas provisórias ou até mesmo projetos de lei.

Paralelo à pesquisa de normas ambientais, foram realizadas análises e interpretações de artigos científicos, monografias, dissertações, teses e livros, além de publicações em revistas e sites a respeito de políticas ambientais e técnicas de sensoriamento remoto. 


\subsection{Estudo de caso}

O Estudo de caso consiste na utilização de um ou mais métodos qualitativos de recolha de informação e não segue uma linha rígida de investigação. Caracteriza-se por descrever um evento ou caso de uma forma longitudinal. O caso consiste geralmente no estudo aprofundado de uma unidade individual.

Sendo assim, o estudo de caso se deu a partir da delimitação de uma sub-bacia do município de Lavras, no intuito de obter informações a respeito da situação legal das propriedades rurais da região, no que compete ao capítulo referente às APP, no Código Florestal.

\section{3. Área de estudo}

A extensão correspondente ao estudo limita-se ao município de Lavras (MG), com 564,495 $\mathrm{km}^{2}$ de área. Contudo, foi delimitada nesse município uma sub-bacia, como unidade experimental, onde foram realizadas análises e propostas formas de zoneamento ambiental. Nas figuras $01 \mathrm{e}$ 02, pode-se observar claramente a localização do município no estado de Minas Gerais:

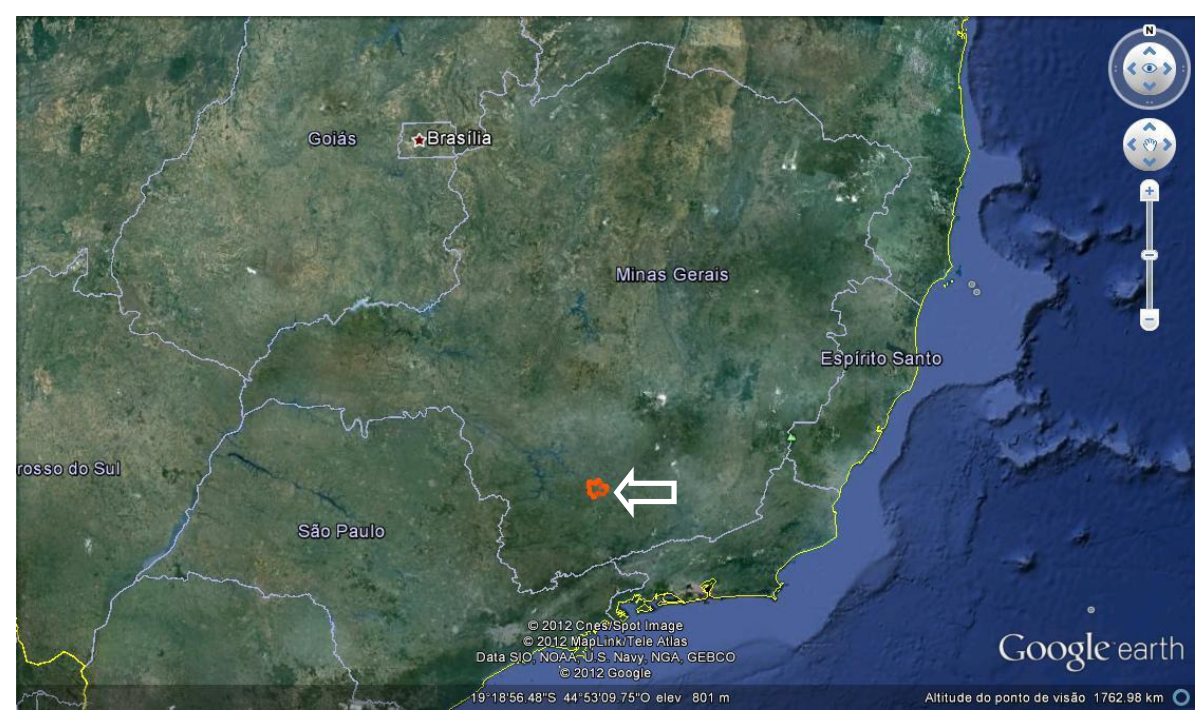

Figura 01: Município de Lavras delimitado no mapa de Minas Gerais.

Fonte: Google Earth 6. 


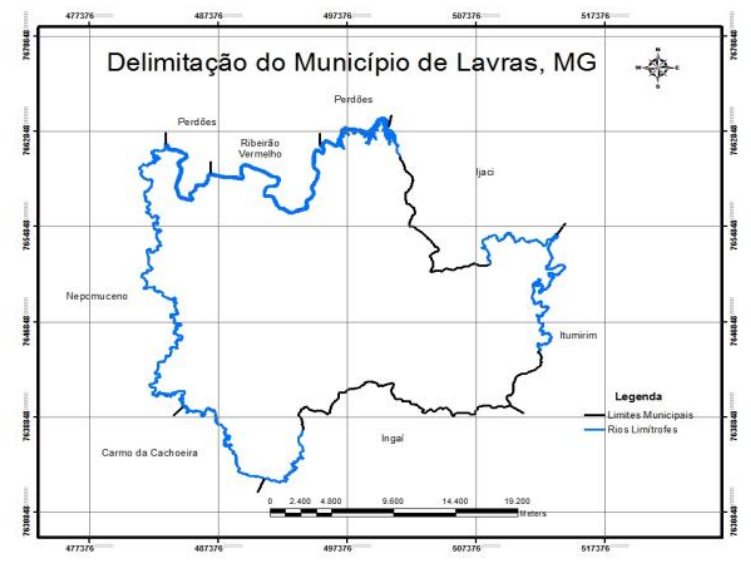

Figura 02: Mapa de delimitação do Município de Lavras, MG.

Fonte: Elaborado pelo autor.

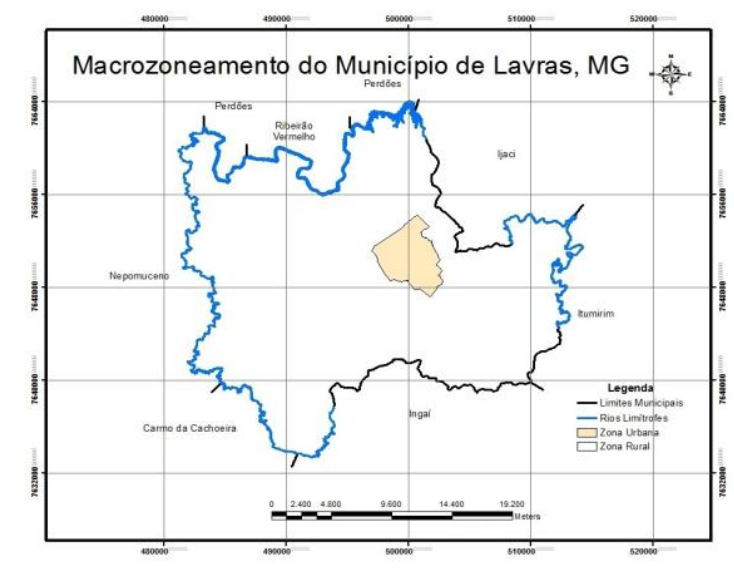

Figura 03: Macrozoneamento do município de Lavras, MG.

Fonte: Elaborada pelo autor.

Devido ao foco nos dispositivos do Código Florestal, pode-se ressaltar que, segundo o art. 4 , § 10, as áreas urbanas recebem tratamento diferenciado quanto à delimitação das APP, devendo-se observar o que é disposto nos respectivos Planos Diretores e Leis Municipais de Uso do Solo, ou seja, são regidas por legislação específica, diferente das propriedades rurais.

Sendo assim, foi necessária a realização de um macrozoneamento municipal, separando área rural e urbana, para que os esforços fossem concentrados na área rural do município. Para isso, a prefeitura municipal de Lavras, forneceu uma esquematização do município em formato DWG (que é a extensão de arquivos de desenho em 2D e 3D do software AutoCAD), composta de arquivos em formato de ponto, linha, polígono e texto.

Os arquivos anteriormente mencionados foram convertidos para o formato Shapefile (que é um formato de arquivo contendo dados geoespaciais em forma de vetor usado por Sistemas de Informações Geográficas), através do aplicativo CAD2Shape 6.0, que realiza a conversão automaticamente.

A partir dos arquivos em formato Shapefile, pode-se realizar o processo de macrozoneamento, através das identificações das layers (nível de informação que representa determinada feição da realidade) relacionadas à área urbana, conforme representado na figura 03.

Excluída a área urbana, foi necessário gerar uma rede de drenagem do município, no intuito de, após a realização desse processo, delimitar a sub-bacia experimental do trabalho. Para gerar essa rede de drenagem, utilizou-se a ferramenta Hidrology, encontrada no item Spatial Analyst Tools do ArcToolBox. A imagem utilizada como suporte foi um mosaico de 04 cenas contendo o município de Lavras, obtidas pelos sensores REIS (RapidEye Earth Imaging System). 
A partir desses dados, pode-se extrair a sub-bacia e identificar nascentes e faixas marginais de curso d'água, sendo essas os únicos tipos de APP presentes na área em estudo.

A seguir, utilizou-se a ferramenta buffer, encontrada no ArcToolBox > Analysis Tolls > Proximity, no intuído de gerar um modelo das APP da sub-bacia em estudo. Depois de gerado os buffers, referentes à $30 \mathrm{~m}$ de APP em leitos de rios (devido aos cursos d'água da sub-bacia terem largura de até $10 \mathrm{~m}$ ) e $50 \mathrm{~m}$ de APP no entorno das nascentes, de acordo com o Código Florestal.

De posse desses dados, foram realizados intersectos entre as APP da sub-bacia e a a layer de classificação de cobertura do solo, cedida pelo Laboratório de Estudos e Projetos em Manejo Florestal, da UFLA. Assim, pode-se determinar o nível de proteção das APP presentes na área de interesse.

\section{RESULTADOS E DISCUSSÃO}

Seguindo os procedimentos descritos no item anterior, referente à metodologia utilizada na área de estudo, foram elaborados os seguintes mapas representativos do município de Lavras:

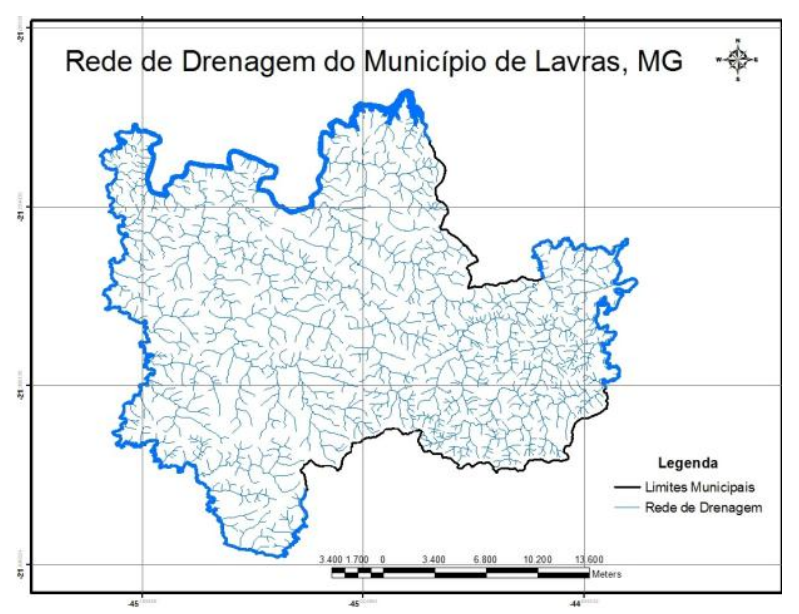

Figura 04: Rede de Drenagem do município de Lavras, MG.

Fonte: Elaborada pelo autor.

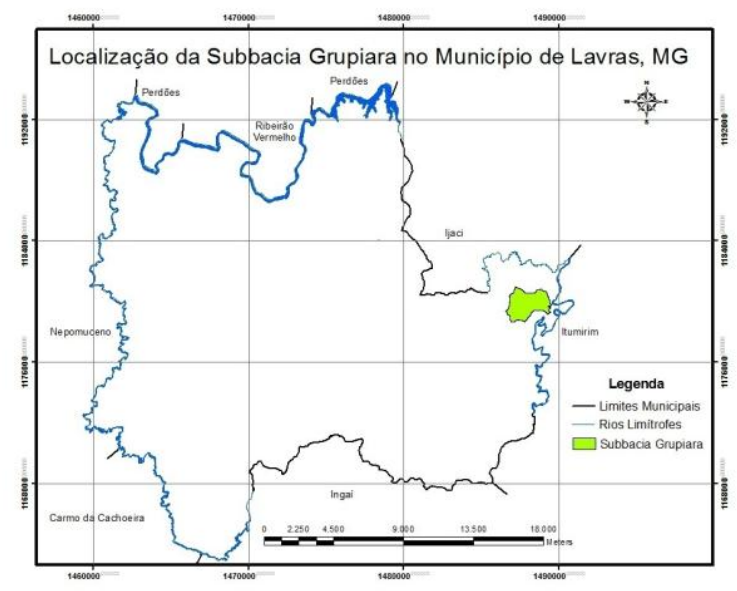

Figura 05: Delimitação da Sub-bacia Grupiara no município de Lavras, MG.

Fonte: Elaborada pelo autor. 


\section{Periódica Eletrônica

A partir da descrição de todas essas características do município, foi possível individualizar a sub-bacia Grupiara, com o auxílio de uma imagem Rapideye, adequando sua área aos limites das propriedades rurais e estradas que a delimitam, como demostrado na figura 06.

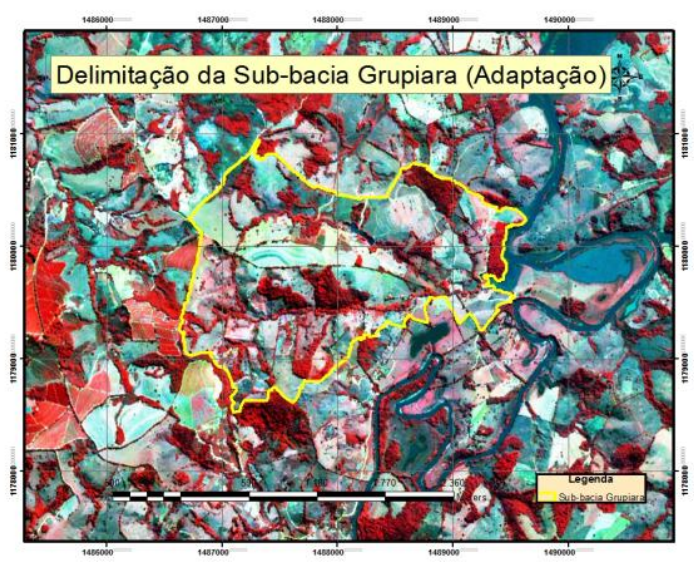

Figura 06: Delimitação Sub-bacia Grupiara Fonte: Elaborada pelo autor.

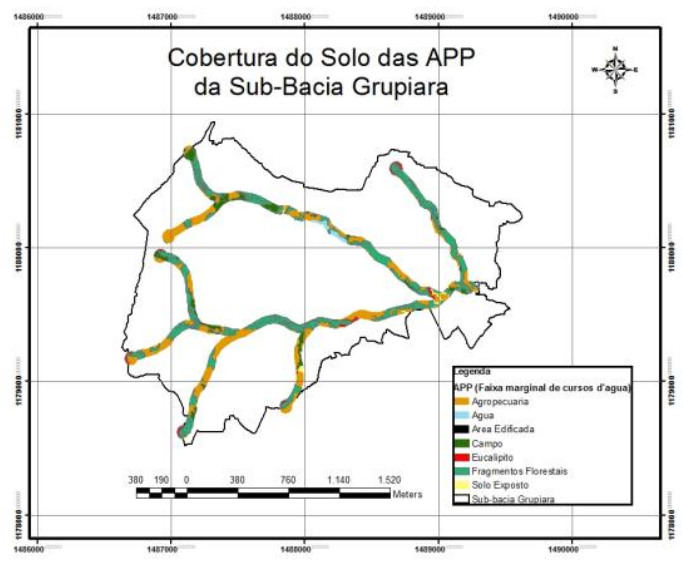

Figura 07: Cobertura do Solo das APP da Sub-bacia Grupiara.

Fonte: Elaborada pelo autor.

Com base nesse mapa, foi calculada a área total da sub-bacia, que representa 408,47 ha da área total do município e, com o auxílio da layer referente à rede de drenagem, realizou-se um buffer dos cursos hídricos e nascentes, no intuito de delimitar as APP da região de estudo. A área total de APP representa 68,61 ha, $16,80 \%$ da área total da sub-bacia.

Após esse procedimento, realizou-se um intersecto com a layer de classificação do uso do solo, podendo-se distinguir os tipos de vegetação ou uso do solo dentro das APP, conforme visualizado na figura 07 . Sendo assim, calculou-se as seguintes áreas e porcentagens por classe de cobertura do solo: 
Quadro 02: Classificação da Cobertura do Solo das APP da Sub-bacia Grupiara.

\begin{tabular}{ccc}
\hline Classe & Área (Ha) & Percentual (\%) \\
\hline Agropecuária & 22,01 & 32,08 \\
Área Edificada & 0,02 & 0,03 \\
Campo & 6,90 & 10,05 \\
Eucalipto & 0,49 & 0,71 \\
Fragmentos Florestais & 38,29 & 55,81 \\
Solo Exposto & 0,91 & 1,32 \\
\hline Total & 68,61 & 100,00 \\
\hline
\end{tabular}

Diante desses dados, observa-se que 44,19\% (cerca de 30,32 ha) das APP encontram-se em desacordo com a legislação, quer seja por uso antrópico ou por degradação natural.

\section{CONCLUSÕES}

Através do auxílio de ferramentas do sensoriamento remoto, pode-se notar que $44,19 \%$ das APP que incluídas na área de estudo encontram-se desprotegidas, degradadas ou foram afetadas por ação antrópica. Isso aponta para a falta de informação população local em relação á preservação dessas importantes áreas, bem como para a baixa fiscalização ambiental.

O sensoriamento remoto demonstrou-se uma importante ferramenta para a regularização ambiental, visto que apresenta boa resolução de imagens e essas podem ser obtidas gratuitamente, ou em parcerias com empresas e universidades.

\section{REFERÊNCIAS BIBLIOGRÁFICAS}

BORGES, L. A. C. ; REZENDE, J. L. P. ; COELHO JÚNIOR, L. M. . Áreas de Proteção Ambiental no Interior de Propriedades Rurais - APP e RL. In: Congresso Internacional de Direito Ambiental, 2009, São Paulo. Direito Ambiental, mudanças climáticas e desastres: impactos nas cidades e no patrimônio cultural. São Paulo : Imprensa Oficial do Estado de São Paulo, v. 2. p. 397-412, 2009. 
BRASIL. Constituição da República Federativa do Brasil de 1988. Disponível em: <http://www.planalto.gov.br/ccivil_03/constituicao/ConstituicaoCompilado,htm>. Acesso em: 03 set. 2012.

BRASIL. Decreto Legislativo no 2, de 03 de fevereiro de 1994. Aprova o texto da Convenção sobre Diversidade Biológica, assinada durante a Conferência das Nações Unidas sobre Meio Ambiente e Desenvolvimento, realizada na cidade do Rio de Janeiro, no período de 5 a 14 de junho de 1992. Disponível em: <www.cesupa.br/saibamais/nupi/doc/CONVDIVERBIO.doc>. Acesso em: 09 set. 2012.

BRASIL. Lei no 4.771, de 15 de setembro de 1965. Revogado pela Lei $n^{0}$ 12.651, de 2012. Disponível em: <http://www2.camara.gov.br/legin/fed/lei/1960-1969/lei-4771-15-setembro-1965369026-publicacaooriginal-1-pl.html>. Acesso em: 03 set. 2012

BRASIL. Lei no 12.651, de 25 de maio de 2012. Dispõe sobre a proteção da vegetação nativa; altera as Leis $\mathrm{n}^{\circ \mathrm{s}}$ 6.938, de 31 de agosto de 1981, 9.393, de 19 de dezembro de 1996, e 11.428, de 22 de dezembro de 2006; revoga as Leis $n^{\circ s} 4.771$, de 15 de setembro de 1965, e 7.754, de 14 de abril de 1989, e a Medida Provisória $n^{\circ}$ 2.166-67, de 24 de agosto de 2001; e dá outras providências. Disponível em: <http://www2.camara.gov.br/legin/fed/lei/2012/lei-12651-25-maio2012-613076-publicacaooriginal-136199-pl.html.> Acesso em: 01 jun. 2012.

BRASIL. Medida Provisória no 571, de 25 de maio de 2012. Altera a Lei $n^{0} 12.651$, de 25 de maio de 2012, que dispõe sobre a proteção da vegetação nativa; altera as Leis $n^{\circ s} 6.938$, de 31 de agosto de 1981, 9.393, de 19 de dezembro de 1996, e 11.428, de 22 de dezembro de 2006; revoga as Leis $n^{0 s} 4.771$, de 15 de setembro de 1965, e 7.754, de 14 de abril de 1989, e a Medida Provisória $n^{\circ} 2.166-67$, de 24 de agosto de 2001. Disponível em: <http://www2.camara.gov.br/legin/fed/medpro/2012/medidaprovisoria-571-25-maio-2012-613083publicacaooriginal-136207-pe.html>. Acesso em: 01 jun. 2012

CAMPOS, F. L. M. . Áreas de Preservação Permanente: Efetividade da legislação e novas propostas para gestão ambiental territorial. Dissertação de Mestrado, Macaé: IFF, Instituto Federal de Educação, Ciência e Tecnologia Fluminense, 2009. 
ECKHARDT, R. R. ; REMPEL, C. ; SALDANHA, D. L. ; GUERRA, T. ; PORTO, M. L. . Análise e Diagnóstico Ambiental do Vale do Taquari - RS - Brasil, Utilizando Sensoriamento Remoto e Técnicas de Geoprocessamento. In: XIII Simpósio Brasileiro de Sensoriamento Remoto, 2007, Florianópolis / SC. Anais do XIII Simpósio Brasileiro de Sensoriamento Remoto. São José dos Campos / SP : Instituto Nacional de Pesquisas Espaciais - INPE, 2007. v. XIII. p. 5191-5198.

LOPES, L.H. Extração de drenagens e delimitação de bacias, ArcGIS 9X. Disponível em: < http://www.youblisher.com/p/114950-Extrair-drenagem-e-bacia-atraves-de-SRTM-no-ArcGIS/>. Acesso em: 05 abr. 2012.

TRENNEPOHL, T. . Direito Ambiental. 4ed. Salvador: JusPodivm, 2009. 